\title{
New Terminologia Anatomica: cranium and extracranial bones of the head
}

\author{
P.P. Chmielewski \\ Division of Anatomy, Department of Human Morphology and Embryology, Faculty of Medicine, \\ Wroclaw Medical University, Wroclaw, Poland
}

[Received: 12 October 2019; Accepted: 17 November 2019; Early publication date: 3 December 2019]

\begin{abstract}
In 2019, the updated and extended version of Terminologia Anatomica was published by the Federative International Programme for Anatomical Terminology (FIPAT). This new edition uses more precise and adequate anatomical names compared to its predecessors. Nevertheless, numerous terms have been modified, which poses a challenge to those who prefer traditional anatomical names, i.e. medical students, teachers, clinicians and their instructors. Therefore, there is a need to popularise this new edition of terminology and explain these recent changes. The anatomy of the head, including the cranium, the extracranial bones of the head, the soft parts of the face and the encephalon, poses a particular challenge for medical students but also engenders enthusiasm in those of them who are astute learners. The new version of anatomical terminology concerning the human skull (FIPAT 2019) is presented and briefly discussed in this synopsis. The aim of this article is to present, popularise and explain these interesting modifications that have recently been endorsed by the FIPAT. Based on teaching experience at the Division of Anatomy/Department of Anatomy at Wroclaw Medical University, a brief description of the human skull is given here. This text can be useful to medical students, teachers, authors and researchers who might want to use the current version of anatomical terminology concerning the human skull. (Folia Morphol 2021; 80, 3: 477-486)
\end{abstract}

Key words: anatomical terminology, anatomical nomenclature, bones of the head, cranium, skull, Nomina Anatomica, Terminologia Anatomica

\section{INTRODUCTION}

The skeleton of the head consists of the cranium and the extracranial bones of the head, i.e. the mandible and the hyoid bone [5]. The cranium consists of two parts, i.e. the cerebral cranium called neurocranium and the visceral cranium called viscerocranium. The term splanchnocranium is not used. Both parts of the cranium are composed of individual bones that are joined by cranial sutures and cranial syndesmoses. Noteworthy, the cranium is not the entire skeleton of the head. Although the traditional term 'skull' has been discarded in order to classify the mandible as one of the extracranial bones of the head, the skull consists of the cranium and the mandible. In physical anthropology and osteology, the following terms are often used: cranium (the skull), calvarium (the brain case), calvaria (the skull vault), calva and calotta (the skull cap).

In early ontogeny, cranial bones develop in connective tissue as membrane bone (Me) forming desmocranium, which is called the calvaria at the later stages of ontogeny. Bone that develops in cartilage (C)

Address for correspondence: Dr. P.P. Chmielewski, PhD, Division of Anatomy, Department of Human Morphology and Embryology, Faculty of Medicine, Wroclaw Medical University, ul. Chałubińskiego 6a, 50-368 Wrocław, Poland, e-mail: piotr.chmielewski@umed.wroc.pl

This article is available in open access under Creative Common Attribution-Non-Commercial-No Derivatives 4.0 International (CC BY-NC-ND 4.0) license, allowing to download articles and share them with others as long as they credit the authors and the publisher, but without permission to change them in any way or use them commercially. 
constitutes the cartilaginous part of embryological cranium, i.e. chondrocranium, that later forms the cranial base. If some parts of a bone develop in membrane and other parts develop in cartilage, the term a mixed bone (Mi) is used [6].

Based on developmental biology and comparative anatomy, the bones of the head can be divided into three types: (1) bones forming the calvarium (the brain case), including bones developing in membrane that form the calvaria (the skull vault) and bones developing in cartilage that form the cranial base (basicranium, the skull base; basis cranii in Latin), (2) bones associated with the nasal capsule that develop in connective tissue (i.e. the nasal bone, the lacrimal bone and the vomer) and bones that develop in cartilage (i.e. the ethmoid bone and the inferior nasal concha) and (3) bones that develop from the visceral arches that can be divided into two groups: (a) immobile bones, i.e. the maxilla, the zygomatic bone and the palatine bone, and (b) mobile bones, i.e. the mandible, the hyoid bone and the auditory ossicles, ossicula auditus seu ossicula auditoria in Latin $[5,6]$.

\section{THE FRONTAL BONE}

In adults, the anterosuperior aspect of the cranium forming the forehead is composed of one pneumatised bone, i.e. the frontal bone (os frontale, from 'frons' meaning 'the bone of the forehead', Me), which encases the cranial cavity anteriorly and contributes to the formation of the calvaria, although this bone is made up of two separate portions at birth and in some individuals throughout life (then the frontal suture, sutura frontalis persistens seu sutura metopica, is present) [8].

The frontal bone consists of: (1) the unpaired squamous part of the frontal bone (squama frontalis), (2) the paired orbital part of the frontal bone (pars orbitalis ossis frontalis) and (3) the unpaired nasal part of the frontal bone (pars nasalis ossis frontalis). The squama has three surfaces, i.e. the external, internal (inner, cerebral) and temporal surface $[4,5]$. Two centres of ossification are visible on the external surface of the squamous part as two frontal eminences (frontal tubers, frontal tuberosities) that are situated over the frontal sinuses. The term 'frontal eminence' (eminentia frontalis) is believed to be more appropriate than 'frontal tubers' as these elevations are subtle in men and more pronounced but not prominent in women. Therefore, this term has recently been changed by the Federative International Programme for Anatomical
Terminology (FIPAT) [cf. 4, 5]. The superciliary arches are situated above the supraorbital margins (previously referred to as the supraorbital borders or ridges) which form the inferior border of the squamous part.

The internal (inner) surface of the frontal bone has poorly defined impressions for cerebral gyri (impressiones gyrorum seu impressions digitatae) [5], eminences of cerebral sulci (juga cerebralia) and inconstantly present arterial grooves (sulci arteriosi). In the midline, there is the groove for the superior sagittal sinus (sulcus sinus sagittalis superioris) that is inferiorly continuous with the frontal crest (crista frontalis) that reaches to the foramen caecum of the frontal bone (foramen caecum ossis frontalis). Although this small foramen is sometimes not blind (in about $1 \%$ of cases) and then it can transmit a small vein from the nasal mucous membrane to the superior sagittal sinus, this well-established term has not been changed by the FIPAT [5], which is a sensible decision.

The temporal surface of the frontal bone forms the anterior part of the temporal fossa (fossa temporalis) that is located posterior to the zygomatic process of the frontal bone. This surface is separated from the external surface of the frontal bone by the temporal line (linea temporalis) that converges to the supraorbital margin to form the zygomatic process.

The nasal part is situated between the two orbital parts where the squama projects inferiorly. This is the smallest part of the frontal bone and it demarcates anteriorly the ethmoidal notch (incisura ethmoidea seu incisura ethmoidalis) [5] in an arch-like fashion. The pointed median structure projecting downwards and forwards from the nasal part of the frontal bone towards the nasal bones is called the nasal spine of the frontal bone (spina nasalis ossis frontalis) [5]. This term has been changed by the FIPAT as this spine should be clearly distinguished from other nasal spines.

Table 1 provides examples of how the modern version of the anatomical terminology (FIPAT 2019) differs from its predecessors (FCAT 1998 and FIPAT 2011).

\section{THE SPHENOID BONE}

The unpaired and pneumatised bone that forms the central part of the cranial base is termed os sphenoideum seu os sphenoidale (sphenoid(al) bone, $\mathrm{Mi})$, although the shorter and traditional term was os sphenoides [1-5]. The shape of this bone resembles a flying bat with its wings extended or a flying wasp [3]. Hence, the historical names os vespiforme, 
Table 1. Comparison of terms from Terminologia Anatomica $(1998,2011)$ and New Terminologia Anatomica (2019) concerning the skull

\begin{tabular}{|c|c|c|}
\hline Terminologia Anatomica (2019) & Terminologia Anatomica $(1998,2011)$ & English Equivalent (2019) \\
\hline Alveoli dentales mandibulae & Alveolus dentalis & Dental alveoli of mandible \\
\hline Alveoli dentales maxillae & Alveolus dentalis & Dental alveoli of maxilla \\
\hline Apertura externa canalis carotidis & Apertura externa canalis carotici & External opening of carotid canal \\
\hline Apertura interna canalis carotidis & Apertura interna canalis carotici & Internal opening of carotid canal \\
\hline Bulla ethmoidea ossea & Bulla ethmoidalis & Bony ethmoidal bulla \\
\hline Canalis carotidis & Canalis caroticus & Carotid canal \\
\hline Canalis facialis & Canalis nenvi facialis & Facial canal \\
\hline Canalis hypoglossus & Canalis nervi hypoglossi & Hypoglossal canal \\
\hline Cellulae ossis ethmoidei & Cellulae ethmoidales & Cells of ethmoid bone \\
\hline Choana cranii & Choana & Choana of cranium \\
\hline Condylus mandibulae & Caput mandibulae & Mandibular condyle \\
\hline Crista ethmoidea maxillae & Crista ethmoidalis & Ethmoidal crest of maxilla \\
\hline Crista ethmoidea ossis palatini & Crista ethmoidalis & Ethmoidal crest of palatine bone \\
\hline Crista petrosa & Crista petrosa* & Petrous ridge \\
\hline Crista sphenoidea & Crista sphenoidalis & Sphenoidal crest \\
\hline Crista supramastoidea & Crista supramastoidea* & Supramastoid crest \\
\hline Foramen alveolare inferius & Foramen mandibulae & Inferior alveolar foramen \\
\hline Foramen ethmoideum anterius & Foramen ethmoidale anterius & Anterior ethmoidal foramen \\
\hline Foramen ethmoideum posterius & Foramen ethmoidale posterius & Posterior ethmoidal foramen \\
\hline Hiatus semilunaris osseus & Hiatus semilunaris & Bony semilunar hiatus \\
\hline Infundibulum ethmoideum osseum & Infundibulum ethmoidale & Bony ethmoidal infundibulum \\
\hline Jugum sphenoideum & Jugum sphenoidale & Sphenoidal yoke \\
\hline Lingula sphenoidea & Lingula sphenoidalis & Sphenoidal lingula \\
\hline Os ethmoideum & Os ethmoidale & Ethmoid(al) bone \\
\hline Os sphenoideum & Os sphenoidale & Sphenoid(al) bone \\
\hline Recessus sphenoethmoideus cranii & Recessus sphenoethmoidalis & Sphenoethmoidal recess of cranium \\
\hline Rostrum sphenoideum & Rostrum sphenoidale & Sphenoidal rostrum \\
\hline Sulcus carotidis & Sulcus caroticus & Carotid sulcus \\
\hline Sulcus chiasmaticus & Sulcus prechiasmaticus & Chiasmatic sulcus \\
\hline
\end{tabular}

os sphexoideum and os sphecoides (from the Greek words 'vespa' and 'sfex', which means 'a wasp'). Interestingly, the name 'sphenoid(al)' has appeared by mistake. In Galen's manuscripts, this bone was referred to as the 'sphecoid bone', which means the 'bone that resembles a wasp', but the copyist made a mistake and wrote 'sphenoid', in Greek 'sfen' means a 'wedge' [6].

The sphenoid has several parts: the body of the sphenoid bone (corpus ossis sphenoidei seu corpus ossis sphenoidalis) [5], the greater wings (alae majores ossis sphenoidei seu alae majors ossis sphenoidalis), the lesser wings (alae minores ossis sphenoidei seu alae minores ossis sphenoidalis) and the pterygoid process (processus pterygoideus). The body of the sphenoid bone is cuboid in shape and has six surfaces. The anterior surface bears the sphenoidal crest (crista sphenoidea seu crista sphenoidalis) [5], a ridge that is a part of the superior wall of the nasal cavity. This crest continues down towards the sphenoidal rostrum (rostrum sphenoideum seu rostrum sphenoidale) [5]. A thin and curved plated called the sphenoidal concha (concha sphenoidea seu concha sphenoidalis) [5] can be observed on both sides. Laterally, there are small openings called openings of sinus of sphenoid(al) bone (apertura sinus ossis sphenoidei seu apertura sinus ossis sphenoidalis) [5].

Although the preferred name for this bone is 'sphenoid' and the term 'sphenoidal' is a synonym, 
only the latter is used in two compounds (i.e. 'sinus of sphenoidal bone' and 'opening of sinus of sphenoidal bone'), which is rather surprising. This is an example of inconsistencies in the new edition of Terminologia Anatomica. The posterior surface fuses with the occipital bone to form the sphenooccipital synchondrosis. The superior surface has planum sphenoideum et jugum sphenoideum that lie in front of the chiasmatic sulcus (sulcus chiasmaticus) [cf. 4, 5]. The sella turcica is bounded anteriorly by the tuberculum sellae and posteriorly by the dorsum sellae. A depression for the pituitary gland (glandula pituitaria seu hypophysis) is called hypophysial (UK)/ /hypophyseal (US) fossa (fossa hypophysialis in Latin) [5], although this is inconsistent with the name of this gland both in Latin and English. The medial ends of the posterior edges of the lesser wings have anterior clinoid processes (sing. processus clinoideus anterior) because they are located in the vicinity of the anterior part of the hypophysial fossa. The lateral parts of the dorsum sellae that project forwards are termed posterior clinoid processes (sing. processus clinoideus posterior). The inconstantly present middle clinoid process (processus clinoideus medius) can be sometimes observed on both sides of the sella turcica.

Each greater wing has five surfaces: the cerebral surface, the temporal surface, the infratemporal surface, the maxillary surface and the orbital surface. The part of this bone that lies in front of the chiasmatic sulcus (sulcus chiasmaticus seu sulcus prechiasmaticus seu sulcus praechiasmaticus in Latin, traditionally termed sulcus chiasmatis) [7] and connects the lesser wings is currently called jugum sphenoideum seu jugum sphenoidale [5]. Interestingly, the sulcus that stretches from the foramen lacerum to the medial side of the anterior clinoid process, lying laterally on both sides of the sella turcica, is officially termed sulcus carotidis seu sulcus caroticus [5].

The lesser wings are two flat and small triangular plates arising by two roots from the anterosuperior edge of the body of the sphenoid bone. At the base of each lesser wing, medially to the anterior clinoid process, there is a bony canal for the optic nerve (CN II), which is called the optic canal (canalis opticus). The superior orbital fissure (fissura orbitalis superior) can be found between the greater and lesser wings where nerves and veins pass.

The paired pterygoid process drops vertically downwards from the junction of the body of the sphenoid bone with the greater wings. Each of them is made up of two laminae: the medial pterygoid plate (lamina medialis) and the lateral pterygoid plate (lamina lateralis) [5]. Between these plates the pterygoid fossa (fossa pterygoidea) can be observed at the posterior aspect. Anteriorly, these plates fuse in the vicinity of the sulcus palatinus major ossis palatini. Since the pterygoid processes are not involved, the term sulcus pterygopalatinus was discarded. The base of this process is pierced by the pterygoid canal (canalis pterygoideus) whose anterior opening communicates with the pterygopalatine fossa. An oblong depression at the root of the medial pterygoid plate is called the scaphoid fossa (fossa scaphoidea, previously known as fossa scaphoides). The tensor veli palatini originates from its lateral end. The pterygospinous process (processus pterygospinosus) [5] is a small and inconstantly present spine that extends from the posterior border of the lateral pterygoid plate where the pterygospinous ligament (ligamentum pterygospinale) attaches.

\section{THE ETHMOID BONE}

The unpaired and pneumatised bone of the neurocranium (although developmentally and topographically this bone belongs to the viscerocranium as it develops as $\mathrm{C}$ within the nasal capsule from three centres) that is located in the superior, medial and lateral parts of the nasal cavity is termed the ethmoid(al) bone, os ethmoideum seu os ethmoidale (from the Greek word 'ethmos' meaning a 'sieve'), although the shorter and traditional name for this bone is os ethmoides [3-5].

Two bony plates of this bone include: (1) the cribriform plate and (2) the perpendicular plate. The cribriform plate is the horizontal plate that is perforated by numerous cribriform foramina (foramina cribrosa) [5] transmitting the olfactory nerve (nervus olfactorius, CN I) from the nasal mucous membrane to the olfactory bulb. This plate fills the ethmoidal notch between the orbital parts of the frontal bone and forms part of the roof of the nasal cavity and the middle part of the anterior cranial fossa. The small bony crest, rising above the cribriform plate and resembling a cock's comb, which gives attachment to the anterior part of the falx cerebri in the anterior cranial fossa, is called the crista galli. The perpendicular plate has two parts, i.e. the smaller superior part above the cribriform plate and the larger inferior part below this plate. This plate descends as the upper part of the nasal septum. Its anterosuperior part articu- 
lates with the nasal spine of the frontal bone and the nasal bones. Its anteroinferior border articulates with the septal cartilage. The posterior border is directed towards the sphenoidal crest, and the inferior border articulates with the vomer.

The main and paired part of this bone that lies on each side of the perpendicular plate is called labyrinthus ethmoideus seu ethmoidalis (ethmoidal labyrinth or so-called 'pannier' of this bone) [5]. This box-shaped and pneumatised portion contains anterior, middle and posterior groups of air cells in paper-thin compartments. The walls of these cellular cavities are so thin and delicate that they are often broken in the disarticulated bone. They are closed by adjacent bones in the intact cranium. Noteworthy, these air cells are currently termed cellulae ossis ethmoidei seu cellulae ethmoideae osseae but not 'cellulae ethmoidales' [5]. The superior surface of the labyrinth has a number of incompletely closed cells. Their walls are completed in the articulated cranium by the edges of the ethmoidal notch of the frontal bone. Crossing this surface on each side are two groves that are converted into canals by articulation with the frontal bone; these are the anterior ethmoidal foramen (foramen ethmoideum anterius seu foramen ethmoidale anterius; old term canalis orbitocranialis) [5] and the posterior ethmoidal foramen (foramen ethmoideum posterius seu foramen ethmoidale posterius; old term canalis orbitoethmoideus) [5] which open on the medial wall of the orbit. The inferior surface of the labyrinth articulates with the maxilla and the palatine bone. The anterior surface of the labyrinth is covered by the lacrimal bone and the upper part of the frontal process of the maxilla. The posterior surface of the labyrinth presents large and irregular cellular cavities that are closed by articulation with the sphenoidal conchae and orbital processes of the palatine bones. The lateral surface of the labyrinth is termed lamina orbitalis labyrinthi ethmoidei or the orbital plate of the ethmoidal labyrinth (previously referred to as lamina papyracea). It constitutes the main part of the medial orbital wall and it covers the middle and posterior ethmoidal cells. This plate articulates anteriorly with the lacrimal bone, posteriorly with the sphenoid bone, superiorly with the orbital plate of the frontal bone and inferiorly with the maxilla and the orbital process of the palatine bone. The medial surface of the labyrinth forms the lateral wall of the nasal cavity. The anterior elevation that is formed by an especially large ethmoidal air cell is termed the bony ethmoidal bulla (bulla ethmoidea ossea seu bulla ethmoidalis) [5]. This bulla compresses the bony ethmoidal infundibulum (infundibulum ethmoideum osseum seu infundibulum ethmoidale osseum) [5], i.e. a deep and curved passage where the anterior ethmoidal cells open.

\section{THE OCCIPITAL BONE}

The unpaired bone that forms the posteroinferior part of the neurocranium is the occipital bone (os occipitale, Mi). Thus, it is a part of the calvaria and a part of the cranial base. This bone is made up of four parts that encircle the foramen magnum, i.e. the squamous part of the occipital bone (squama occipitalis), the basilar part of the occipital bone (pars basilaris ossis occipitalis) and the paired lateral part (clinically, the 'condylar part') of the occipital bone (pars lateralis ossis occipitalis) [6]. The squamous part has two surfaces, which remain unnamed, i.e. the convex external surface and the concave internal surface. The former has a site of appearance of the ossification nucleus in the centre where the bone is most convex which is called the external occipital protuberance (protuberantia occipitalis externa). There are two ridges that diverge laterally from this site that are called superior nuchal lines (sing. linea nuchalis superior), although the previous term (linea nuchae superior) is often used. Supreme (highest, Terminologia Anatomica 1998) nuchal lines (sing. linea nuchalis suprema, previously linea nuchae suprema) [cf. 4, 5] are encountered above and parallel and are less conspicuous. The trapezius muscle attaches between these two paired lines. Transverse ridges between the superior nuchal lines and the foramen magnum are called inferior nuchal lines (sing. linea nuchalis inferior, previously linea nuchae inferior). The external occipital crest descends from the external occipital protuberance towards the foramen magnum.

The internal (inner, cerebral) surface of the squamous part bears the cruciform eminence (eminentia cruciformis, previously eminentia cruciata) [5] that gives rise to the groove for the transverse sinus passing laterally on each side, the ascending grove for the superior sagittal sinus and the internal occipital protuberance (protuberantia occipitalis interna) in the middle from which the internal occipital crest (crista occipitalis interna) descends to the posterior semicircumference of the foramen magnum. The upper depressions for the occipital lobes of the cerebrum 
are called cerebral fossae (sing. fossa cerebralis) and the lower depressions for the cerebellum are called cerebellar fossae (sing. fossa cerebellaris). Each lateral part contributes to the union of the cranium with the vertebral column and therefore carries the occipital condyle (condylus occipitalis) on its inferior surface. Interestingly, the name for the short canal that is located at the base of the occipital condyle, i.e. posteroinferiorly to the jugular tubercle and between the jugular process and the occipital condyle has been changed from canalis nervi hypoglossi to canalis hypoglossus, hypoglossal canal in English [5]. Similar changes occurred in respect of other bony canals for nerves. Interestingly, the small and shallow depression that is sometimes present at the dorsal aspect of the foramen magnum in the midline between the cerebellar fossae at the lower end of the internal occipital crest, is officially termed fossa vermiana, i.e. the vermian fossa in English [5], which is a traditional term, although the term eminentia triangularis is also used in the anatomical literature for its common variant. The basilar part fuses with the body of the sphenoid bone at age 18 to form a single bone and a smooth and sloping area for the medulla oblongata and the pons, i.e. clivus, this bone is sometimes referred to as os basilare [6].

\section{THE PARIETAL BONES}

The parietal bone (os parietale, from 'paries' meaning 'wall', Me) is a paired bone that forms the middle part of the calvaria (the skull vault). It has the external surface and the internal surface and four borders (frontal, sagittal, occipital and squamosal - not 'squamous') that are separated by four angles (frontal, occipital, mastoid and sphenoidal). The prominence that is located near the midline of the external surface is called the parietal eminence (or parietal tuber), eminentia parietalis seu tuber parietale [5]. The curved line for the attachment of the temporalis is termed the inferior temporal line (linea temporalis inferior) and the curved line for the attachment of the temporal fascia is termed the superior temporal line (linea temporalis superior). In the vicinity of the posterosuperior part of the parietal bone there is a small opening for an emissary vein called the parietal foramen (foramen parietale).

\section{THE TEMPORAL BONES}

The temporal bone (os temporale, Mi, from the Latin word 'tempus' meaning 'time', so this is the 'time bone' just like the temporalis is the 'time muscle'; noteworthy, first grey hairs often appear in the pertinent region of the head, which is a critical juncture in life) contributes to the formation of the lateral wall and the base of the cranium. The structure of this bone is complicated because it contains important nerves, vessels and peripheral receptors for both the special sense of hearing and the maintenance of equilibrium. A number of muscles and ligaments attach to this bone. It also articulates with the mandible by a movable joint, i.e. the temporomandibular joint (TMJ).

Developmentally, each temporal bone consists of three parts: the squamous part (pars squamosa), the petrous part (pars petrosa, including the mastoid part, pars mastoidea) and the tympanic part (pars tympanica) [6]. In clinical anatomy, the mastoid part and the 'styloid part' are sometimes distinguished. Noteworthy, the mastoid part does not have a nucleus for independent ossification and arises from the petrous part, while the styloid part comprises the styloid process (from the Greek word 'stylos' meaning a 'pillar') which together with the stylohyoid ligament is a remnant of the second visceral arch [6]. Therefore, this traditional and clinical description is unfortunate from an embryological standpoint.

The squama is a thin, vertical and often translucent plate that forms the anterosuperior part of this bone. Its smooth external surface is called the temporal surface (facies temporalis ossis temporalis). This surface affords attachment to the temporalis muscle and is marked posteriorly by the middle temporal artery grooving sulcus arteriae temporalis mediae. The mandibular fossa (the glenoid fossa of the temporal bone, fossa mandibularis) is bounded anteriorly by the articular tubercle (tuberculum articulare) and articulates with the mandibular condyle to form the TMJ. The cerebral surface bears marks of the brain and arteries, i.e. impressiones gyrorum (seu digitatae), juga cerebralia et sulci arteriosi.

The zygomatic process of the temporal bone (processus zygomaticus ossis temporalis) is a narrow bony arch that projects forwards from the inferior part of the squama to join the temporal process of the zygomatic bone and form the zygomatic arch (arcus zygomaticus).

The zygomatic process has two roots, i.e. the anterior root (the articular tubercle) and the posterior root, with the mandibular (glenoid) fossa between them, and two borders, i.e. the thin superior border 
that serves for the attachment of the temporal fascia and the inferior border that affords attachment to some fibres of the masseter. Interestingly, the traditional name for the crest that projects posteriorly as the continuation of the suprameatic line stretching from the base of the zygomatic process, forming the posteroinferior border of the temporal fossa, has been endorsed by the FIPAT and is officially termed supramastoid crest (crista supramastoidea) [5].

The longest bony canal of the temporal bone that originates on the floor of the internal acoustic meatus (internal auditory canal), stretching laterally to the axis of the petrous part and ending with the foramen stylomastoideum (stylomastoid foramen) is officially termed canalis facialis seu canalis nervi facialis (facial canal in English) [5] to match other similar modifications. Interestingly, the widest canal of the temporal bone is termed canalis carotidis seu canalis caroticus and the official names for its two openings are: apertura externa canalis carotidis et apertura interna canalis carotidis (seu apertura externa canalis caroticus et aperture interna canalis caroticus, respectively) [5].

\section{THE FACIAL BONES}

The facial bones are either associated with the nasal capsule or immobile (fixed) bones that are derived from the visceral arches, see Introduction. The mandible is neither part of the cranium nor part of the facial skeleton. Therefore, it has been classified as the extracranial bone of the head [5].

The nasal bone (os nasale) is a small and paired bone that has two unnamed surfaces, i.e. the external and the internal surface and four unnamed borders, i.e. superior, inferior, medial and lateral. It joints the contralateral bone to form the skeletal support for the nasus externus. Only two terms in the new edition of Terminologia Anatomica [5] refer to this bone, i.e. the ethmoidal groove (sulcus ethmoideus seu sulcus ethmoidalis) and the nasal foramen (foramen nasalis). These bones are remarkably variable in different people

The lacrimal bone (os lacrimale) is a paired and exceptionally small and fragile bone of the face that is located in the anterior part of the medial wall of the orbit, just behind the frontal process of the maxilla. This bone presents two unnamed surfaces and four unnamed borders. Thus, this bone resembles an open booklet and the spine-like part is termed the posterior lacrimal crest (crista lacrimalis posterior).
To the front of this crest runs the lacrimal groove (sulcus lacrimalis ossis lacrimalis). Together with the adjacent groove and the anterior lacrimal crest of the frontal process of the maxilla they form the fossa for the lacrimal sac, fossa sacci lacrimalis (Terminologia Anatomica, section Orbita) [5]. The posterior lacrimal crest ends inferiorly in a small bony hook termed the lacrimal hamulus (hamulus lacrimalis) which articulates with the lacrimal tubercle of the maxilla.

The zygomatic bone (os zygomaticum, after Riolan), which is casually referred to as the 'cheekbone' (os malare) and 'zygoma' (Galen) in clinical anatomy, is a paired bone that is one of the strongest bones of the cranium [6]. It connects the frontal bone with the temporal bone, thereby contributing to the zygomatic arch (arcus zygomaticus), i.e. the site of origin of the masseter, and strengthening the facial skeleton. Its central part is often referred to as the 'body of the zygomatic bone' (corpus ossis zygomatici) in clinical anatomy, although this term remains unofficial [5] and has not been endorsed by the FIPAT. The body has three surfaces, i.e. the surface and the zygomaticofacial foramen (foramen zygomaticofaciale). The zygomatic bone presents three surfaces, i.e. the lateral (malar), orbital and temporal surfaces, five borders and two processes, i.e. the superior frontal process which articulates with the zygomatic process of the frontal bone and the lateral temporal process which articulates with the zygomatic process of the temporal bone.

The maxilla is a paired, pneumatised and the largest bone of the face [6]. This bone comprises the body of the maxilla (corpus maxillae) with its four surfaces, i.e. anterior, infratemporal, nasal and orbital, and four processes of the maxilla, i.e. the frontal process, the zygomatic process, the palatine process and the alveolar process. The body contains a large sinus called the maxillary sinus (sinus maxillae seu sinus maxillaris osseus) [5], which communicates with the nasal cavity through an opening on the medial (nasal) wall of the maxilla that is termed hiatus of maxilla (hiatus maxillae seu hiatus maxillaris osseus) [5]. Posterior to the frontal process and anterior to this hiatus, the lacrimal groove of maxilla (sulcus lacrimalis maxillae) can be observed, which together with the lacrimal bone and the inferior nasal concha form the nasolacrimal canal (canalis nasolacrimalis). The anterior (traditionally termed 'malar') surface (facies anterior maxillae) has the infraorbital foramen (foramen infraorbitale) and the canine fossa (fossa 
canina) below, where the Levator anguli oris origins. The infratemporal surface (facies infratemporalis maxillae) is separated from the anterior surface by the zygomatic process and has several small perforations for the nerves and vessels to the upper teeth. The maxillary tuberosity (tuber maxillae seu eminentia maxillae) [5] is a rounded and roughened elevation on the infratemporal surface of the body of the maxilla that is located posterior to the most distal molar of the maxillary arch. This important landmark is perforated by the posterior superior alveolar foramina (foramina alveolaria superiora posteriora), where the posterior superior alveolar nerve along with blood vessels enter the bone from the posterior. The nasal surface is continuous inferiorly with the superior surface of the palatine process. The orbital surface of the body is flat, smooth and triangular in shape. The lacrimal notch (incisura lacrimalis) is located just behind the frontal process. The infraobrital groove (sulcus infraorbitalis) originates in the vicinity of the posterior border of the orbital surface and is anteriorly converted into the infraorbital canal (canalis infraorbitalis) which opens on the anterior surface as the infraorbital foramen (foramen infraorbitale). The frontal process of the maxillae (processus frontalis maxillae) projects upwards and joints the nasal part of the frontal bone. Its lateral surface is divided into two parts by the anterior lacrimal crest (crista lacrimalis anterior), which is continuous downwards with the infraorbital margin. The zygomatic process of the maxillae (processus zygomaticus maxillae) articulates with the zygomatic bone. The palatine process (processus palatinus) forms most (about three quarters) of the hard bony palate by joining the contralateral process in the midline where the nasal crest of maxilla (crista nasalis maxillae) rises on the superior surface. This part faces the nasal cavity and articulates with the inferior edge of the vomer. Both openings that lead into the incisive canals (canales incisivi) are located in the vicinity of the anterior end of the nasal crest on the superior surface. The alveolar process (processus alveolaris maxillae) is the thickest and most spongy part of the maxilla. Its inferior border is called the alveolar arch of the maxilla (arcus alveolaris maxillae). This part has eight dental alveoli or dental sockets of the maxilla (alveoli dentales maxillae) for the eight upper teeth.

The palatine bone (os palatinum) is an L-shaped bone that is situated in the posterior part of the nasal cavity, between the maxilla and the pterygoid process of the sphenoid bone. Each palatine bone extends from the posterior quarter of the hard palate to the floor of the orbit. It also contributes to the formation of the floor and lateral wall of the nasal cavity. It enters into the formation of the pterygopalatine, pterygoid and infratemporal fossae [6]. Thus, although this bone is small, it contributes to the formation of some of the cranial cavities, including the orbit, the oral cavity, the nasal cavity and the three fossae. Each palatine bone has two plates, i.e. the horizontal plate (lamina horizontalis ossis palatini, previously lamina palatina ossis palatini) and the perpendicular plate (lamina perpendicularis ossis palatini). The former complements the palatine process posteriorly to form the hard bony palate. Its medial border meets the medial border of the contralateral bone to form the nasal crest with the vomer between its lips. The latter is longer and adjoins the nasal surface of the maxilla. On its nasal surface it has ethmoidal and conchal crests. The palatine bone has three processes, i.e. the pyramidal process (processus pyramidalis), which projects posteriorly and laterally from the junction of the horizontal and perpendicular plates, the larger orbital process (processus orbitalis) and the smaller sphenoidal process (processus sphenoideus seu processus sphenoidalis) [5] with the sphenopalatine notch (incisura sphenopalatina) between them. The sphenoid bone covers this notch and converts it into the sphenopalatine foramen.

The inferior nasal conchae (concha nasalis inferior), previously termed the 'inferior nasal turbinate', is a paired curved bony plate that extends horizontally along the lateral wall of the nasal cavity. Unlike the other conchae (parts of the ethmoid bone), this is an independent bone. It has three processes: maxillary (processus maxillaris), lacrimal (processus lacrimalis) and ethmoidal (processus ethmoidalis). This bone has two surfaces (lateral and medial), two borders (superior and inferior) and two extremities.

The vomer (vomer, after Fallopio, Bartholin used the term aratrum, both these terms refer to the fact that this bone resembles the Roman ploughshare) is an unpaired and roughly quadrilateral plate that forms part of the bony nasal septum [6]. Its superior edge is thicker that the other edges and embraces the sphenoidal rostrum with the wings called alae vomeris (sing. ala of vomer, ala vomeris). The upper half of the anterior edge articulates with the perpendicular plate of the ethmoid, and the lower part with the cartilaginous nasal septum. The inferior edge articulates with the nasal crest of the maxilla and the 
palatine bone. The free posterior edge constitutes the free posterior border of the bony nasal septum separating the right and left posterior nasal aperture of cranium, i.e. right and left choana of cranium (choana cranii in Latin) [5].

\section{EXTRACRANIAL BONES OF THE HEAD: THE MANDIBLE}

The mandible (mandibula, which is derived from the Latin word mandere, which means 'to chew, masticate or devour') is classified as the extracranial bone of the head [5] and the only mobile skull bone. This is the largest and the strongest facial bone that is heavily formed to carry the lower teeth and the muscles of mastication [6]. This bone affords attachment to the muscles of the tongue and floor of the mouth. Its horseshoe shape is determined by its development and function.

The body of the mandible (corpus mandibulae) has two unnamed surfaces: facies externa and facies interna. On the external surface in the midline there is a vertical ridge where two halves are fused to form the junction called symphysis (syndesmosis) mandibulae seu menti [5]. In general, the structure and relief of the body are determined by the teeth and the function of this part which form the mouth. The inferior border is called the base of the mandible (basis mandibulae). The upper part, i.e. the alveolar part (pars alveolaris mandibulae) bears lower teeth. Consequently, the alveolar arch has the dental alveoli (alveoli dentales mandibulae) with the interalveolar septa (septa interalveolaria mandibulae) with the interradicular septa (septa interradicularia mandibulae) that can be found in some alveoli. Corresponding depressions for the former septa that are visible on the external surface of the body are called the alveolar yokes of mandible (juga alveolaria mandibulae). On the external surface of the body there is a ridge at the symphysis, which is known as the mental protuberance (protuberantia mentalis). The mental tubercle (tuberculum mentale) lies on each side of this protuberance. Laterally, there is the mental foramen (foramen mentale), which is an opening of the mandibular canal (canalis mandibulae), transmitting nerves and vessels. To the back of the mental foramen is the oblique line (linea obliqua mandibulae), which runs upwards. Two mental spines or 'genial tubercles' (spinae mentales - spina mentalis superior et inferior) project from the inner surface of the symphysis as the side of attachment of the genioglossus muscle. Inferiorly and on both sides of the mental spine lies the digastrics fossa (fossa digastrica) as the side of attachment of the digastric muscle. The mylohyoid line (linea mylohyoidea) runs backwards and upwards and passes obliquely towards the ramus.

The ramus of the mandible or 'mandibular ramus' (ramus mandibulae) is quadrilateral in shape and has two surfaces, i.e. the external and internal surfaces (facies lateralis et medialis), four unnamed borders (superior, inferior, anterior et posterior) and two processes (processus coronoideus mandibulae et processus condylaris). On the inner surface of the ramus is the inferior alveolar foramen (foramen alveolare inferius, previously 'foramen mandibulae') [5], leading to the mandibular canal mentioned above. The medial edge of this foramen projects as the lingula mandibulae, to which the sphenomandibular ligament attaches. The mylohyoid groove (sulcus mylohyoideus) originates behind the lingula and passes downwards and forwards. The inferior and posterior borders of the ramus arise from the body obliquely and posteriorly to form the angle of the mandible or 'mandibular angle' (angulus mandibulae). The anterior border of the ramus bears the temporal crest (crista temporalis) [5], where the temporalis attaches. The superior border has two processes: the condylar process has the mandibular condyle (condylus mandibulae seu caput mandibulae seu capitulum mandibulare) [5] which is covered by cartilage. The condyle or head is continuous with the neck of the mandible (collum mandibulae) which has the pterygoid fovea (fovea pterygoidea) on its inner surface. The coronoid process of the mandible (processus coronoideus mandibulae) [5] is the 'muscular' and anterior process that has a rough area for attachment of the temporalis muscle. Both processes are separated by the mandibular notch (incisura mandibulae).

\section{EXTRACRANIAL BONES OF THE HEAD: THE HYOID BONE}

The hyoid bone (os hyoideum, previously os hyoides), named from its resemblance to the Greek letter $\mathrm{U}$, is situated at the base of the tongue, between the mandible and the larynx, and is suspended from the tips of the styloid processes by the stylohyoid ligaments. It consists of the body (corpus ossis hyoidei) and two pairs of horns, i.e. the lesser horns and the greater horns, cornu minus et cornu majus ossis hyoidei, respectively. 


\section{CONCLUSIONS}

The new terminology concerning the cranium and the extracranial bones of the head uses more appropriate anatomical terms. Although the old tradition has been respected, more precise and anatomically adequate terms are currently being used. Therefore, the new version of the anatomical terminology deserves attention and should be used in both didactic and clinical practice.

Conflict of interest: None declared

\section{REFERENCES}

1. Chmielewski PP. New Terminologia Anatomica highlights the importance of clinical anatomy. Folia Morphol. 2020; 79(1): 15-20, doi: 10.5603/FM.a2019.0048, indexed in Pubmed: 31025701.

2. Chmielewski PP, Strzelec B. Should Terminologia Anatomica be revised and extended? A critical literature review. Folia Morphol. 2020; 79(1): 1-14, doi: 10.5603/ FM.a2019.0047, indexed in Pubmed: 31025702.

3. Chmielewski PP, Domagała ZA. Terminologia Anatomica and its practical usage: pitfalls and how to avoid them. Folia Morphol. 2020; 79(2): 198-204, doi: 10.5603/ FM.a2019.0086, indexed in Pubmed: 31411339.

4. FIPAT. Terminologia Anatomica. International Anatomical Terminology. 2nd edition. Georg Thieme Verlag, 2011.

5. FIPAT. Terminologia Anatomica. International Anatomical Terminology. 3rd edition. Georg Thieme Verlag, 2019.

6. Prives M, Lysenkov N, Bushkovich V. Human anatomy. MIR Publishers, Moscow 1985.

7. Strzelec B, Chmielewski PP, Gworys B. The Terminologia Anatomica matters: examples from didactic, scientific, and clinical practice. Folia Morphol. 2017; 76(3): 340-347, doi: 10.5603/FM.a2016.0078, indexed in Pubmed: 28026851.

8. Zdilla MJ, Russell ML, Koons AW, et al. Metopism: a study of the persistent metopic suture. J Craniofac Surg. 2018; 29(1): 204-208, doi: 10.1097/SCS.0000000000004030, indexed in Pubmed: 29049140. 